\title{
Localization of caspase 12 in masseter muscle of $m d x$ mice during regeneration
}

\author{
Shinichi Abe \\ Oral Health Science Center HRC7 and Department of Anatomy, Tokyo Dental College
}

\begin{abstract}
The $m d x$ mouse, a model of muscular dystrophy, lacks dystrophin, a cell membrane protein. It is known that this lack of dystrophin results in muscle fiber necrosis from 2 weeks after birth, and the majority of necrotic fibers are replaced by regenerated fibers by 4 weeks of age. Recent studies reported the detection of mitochondrial and endoplasmic reticulum stress proteins during muscle fiber necrosis in $m d x$ mice, but did not histologically localize them to determine the timing of their expression during the process from cell necrosis to regeneration. Therefore, in this study, we investigated histological localization and gene-level expression in the $m d x$ mouse masseter muscle of caspase-12 protein (among the caspases, which are cell stress-related genes) involved in the endoplasmic reticulum stress pathway. We observed caspase-12 expression in muscle cells that seemed to be in the process of necrosis in the $m d x$ mouse masseter muscle at 2 weeks after birth, but not in regenerated muscle cells with centrally located nuclei observed at 3 to 4 weeks of age. These results suggest that due to the lack of dystrophin, it becomes difficult for muscle cells to maintain their morphology, and endoplasmic reticulum stress occurs to maintain cell morphology during the process of cell necrosis.
\end{abstract}

KEY WORDS: muscle anti-aging, regeneration, muscle fiber, masseter

\section{Introduction}

Duchenne muscular dystrophy (DMD) is caused by a lack of dystrophin in the subsarcolemmal cytoskeleton ${ }^{1)}$. The $m d x$ mouse, a model of muscular dystrophy, arose from a spontaneous mutation in inbred C57BL/10 mice, and was discovered in 1984 by Bulfield et $\mathrm{al}^{2}$. . Like DMD patients, $m d x$ mice lack dystrophin, which results in muscle fiber necrosis and regeneration from 2 weeks after birth, and the majority of necrotic muscles of the extremities are replaced with regenerated muscles by 4 weeks of age ${ }^{3-5)}$. A similar phenomenon was reported to occur in the branchial arch-derived masseter muscle of $m d x$ mice ${ }^{6}$. Thus, $m d x$ mice have been used as the optimal model for studying the pathogenesis of muscle necrosis ${ }^{7)}$.

In recent years, an apoptosis-like phenomenon that occurs during necrosis has been discussed ${ }^{8,9)}$. In regard to this, a study investigating overexpression of the caspase- 3 gene related to mitochondrial-mediated apoptosis has noted that, in addition to necrosis, a phenomenon similar to apoptosis may occur in the muscle fibers of the $m d x$ mouse model of muscular dystrophy ${ }^{10)}$. Another study has reported the occurrence of not only mitochondrial- but also endoplasmic reticulum-mediated intracellular stress during muscle fiber necrosis in $m d x$ mice ${ }^{11)}$. These studies have shown that cellular necrosis occurred via intracellular stress, as demonstrated for apoptosis, even in the process of necrosis; however, no study has investigated the tissue localization of caspases. In this study, we examined the localization of caspase 12 in the masticatory muscle of $\mathrm{mdx}$ mice using an immunohistochemical method.

\section{Material and Methods}

\section{Specimens}

Three groups of $10 \mathrm{mdx}$ male mice $(\mathrm{C} 57 \mathrm{BL} / 10 \mathrm{ScSn})$ at the ages of 2, 3, 4 weeks, respectively, and groups of 10 control mice (B10 Scott Snells) at the corresponding ages were used in the study. The mice were anesthetized with pentobarbital, and sacrificed according to the Guidelines for Animal Experiments of Tokyo Dental College. The superficial layers of the left masseter muscle from all mice were used for morphological examination and immunohistochemical analysis.

\section{Frozen sections}

The masseter muscle tissue was embedded in Tissue-Tek OCT compound (Sakura Finetechnical Co., Ltd., Tokyo, Japan), placed in isopentane $\left(-160^{\circ} \mathrm{C}\right)$ and refrigerated with liquid nitrogen to quicken the freezing process. Subsequently, according to the conventional method, serial fresh-frozen sections of $8 \mu \mathrm{m}$, perpendicular to the grain of muscle fibers, were prepared at $-20^{\circ} \mathrm{C}$ in a cryostat. Some frozen sections were stained with hematoxylin eosin (HE) after fixation in 4\% paraformaldehyde in phosphatebuffered saline (PBS), $\mathrm{pH}$ 7.4.

\section{Antibody}

The following antibody was used in this study: Polyclonal Rabbit Anti-Active Caspase-12: 3015-100 (Bio Vision Research Products, CA, USA), dilution 1:500, $4^{\circ} \mathrm{C}$ overnight. 


\section{Immunohistochemistry}

Immunohistochemistry was performed using the Vectastain Elite ABC Kit, Rabbit IgG (Vector Laboratories, Inc., USA) according to the manufacturer's instructions. Some frozen sections were transferred into PBS after fixation in $4 \%$ paraformaldehyde in PBS for 5 minutes. To quench endogenous peroxidase, the sections were treated with $0.3 \% \mathrm{H}_{2} \mathrm{O}_{2}$ in methanol for 30 minutes, followed by rinsing with PBS. Sections were next treated with $0.1 \%$ goat normal serum in PBS at room temperature for 30 minutes and reacted with the above primary antibody diluted in PBS. The sections were treated with biotinylated secondary antirabbit antibody for 30 minutes, followed by $\mathrm{ABC}$ reagent for 30 minutes at room temperature. Next, they were incubated with peroxidase substrate solution (DAB Solution, Wako Chemicals, USA, Inc.) at room temperature for 3 minutes, and then transferred into distilled water. Finally, they were stained with methyl green for counterstaining, dehydrated in ethanol, and mounted with Pristine Mount (Falma, Inc., Japan).

\section{Reverse transcription polymerase chain reaction analysis}

From mice in each age group, the muscle was removed and snap-frozen in liquid nitrogen. mRNA at each stage was extracted using a QuickPrep micro mRNA Purification Kit (Amersham Pharmacia Biotech UK Ltd.), and cDNA was prepared using Ready-To-Go (Amersham Pharmacia Biotech UK Ltd.). After the optimal PCR conditions for all primers were determined, experiments were performed using a LightCycler ${ }^{\mathrm{TM}}$ (Roche Diagnostics, Mannheim, Germany), which allows RNA quantification. Experiments were performed according to the standard protocol for the LightCycler ${ }^{\mathrm{TM}}$. A ready-to-use $\mathrm{LC}$ FastStart DNA Master SYBR Green I (Roche) was used as a hotstart PCR reaction mix for the LightCyclerTM. A series of dilutions of a cDNA synthesis $(4.0 \mathrm{ng} / \mu \mathrm{l})$ were made, and dilution ratios of $1 / 10^{5}, 1 / 10^{6}, 1 / 10^{7}, 1 / 10^{8}$, and $1 / 10^{9}$ were used. The PCR product contained $10.2 \mu \mathrm{l}$ of sterile water and $5 \mu \mathrm{l}$ of diluted control cDNA, $1.6 \mu \mathrm{l}$ of $25 \mathrm{mM} \mathrm{MgCl}$, and $2 \mu \mathrm{l}$ LC FastStart DNA Master SYBR Green I containing SYBR Green I (1/60,000 dilution). In addition, $0.6 \mu \mathrm{l}$ of each forward and reverse primer were added to a final reaction volume of $20 \mu \mathrm{l}$. The mRNA sequence of the caspase-12 obtained from the genome database was used to design specific primers (Biogene Ltd.), and had the following sequences: caspase-12 (forward, 5'-AGGATGATGGACCTCAGA-3'; reverse, 5'-GCTGTCAGCATTAGATGTGA-3'; Accession No. NM_009808). PCR mixtures ( $20 \mu \mathrm{l}$ each) prepared for caspase-12 were added to the glass portion of a capillary. Initial denaturation at $95^{\circ} \mathrm{C}$ for $10 \mathrm{~min}$ was followed by 45 cycles of denaturation at $95^{\circ} \mathrm{C}$ for $10 \mathrm{sec}$, an annealing step at $60^{\circ} \mathrm{C}$ for $10 \mathrm{sec}$, and an extension step at $72^{\circ} \mathrm{C}$ for $8 \mathrm{sec}$. Gene amplification was performed according to a melting program of $70^{\circ} \mathrm{C}$ for $15 \mathrm{sec}$, and fluorescence was continuously monitored at a rate of $0.1 \mathrm{deg} / \mathrm{s}$ from 70 to $95 \mathrm{deg}$. Fluorescence channel F1 $(530 \mathrm{~nm})$ was used, and the gain volumes for caspase- 12 were $82.6^{\circ} \mathrm{C}, 89.6^{\circ} \mathrm{C}, 91.4^{\circ} \mathrm{C}$ and $82.6^{\circ} \mathrm{C}$, respectively.

The numerical values of each caspase- 12 mRNA expression were normalized by dividing the expression of housekeeping GAPDH mRNA to finally obtain the relative expression level of mRNA. The primers for GAPDH had the following sequences: forward, 5'-TGA ACGGGAAGCTCACTGG-3'; reverse, 5'TCCACCACCCTGTTGCTGTA-3'; Accession: NM_008084.

\section{Statistical analysis}

Student's t-test was applied to pairs of each time-point values in this study and a $p$ value of $<0.05$ was considered significant.

\section{Results}

\section{Morphological observations}

Features suggestive of muscle cell necrosis were noted in the masseter muscle of 2-week-old $m d x$ in comparison with control mice. In addition, a small number of regenerated muscle fibers with centrally located nuclei were seen in the masseter muscle of 3 -week-old $m d x$ mice, and a larger number of regenerated muscle fibers in that of 4-week-old $m d x$ mice (Figure 1).

\section{B10}
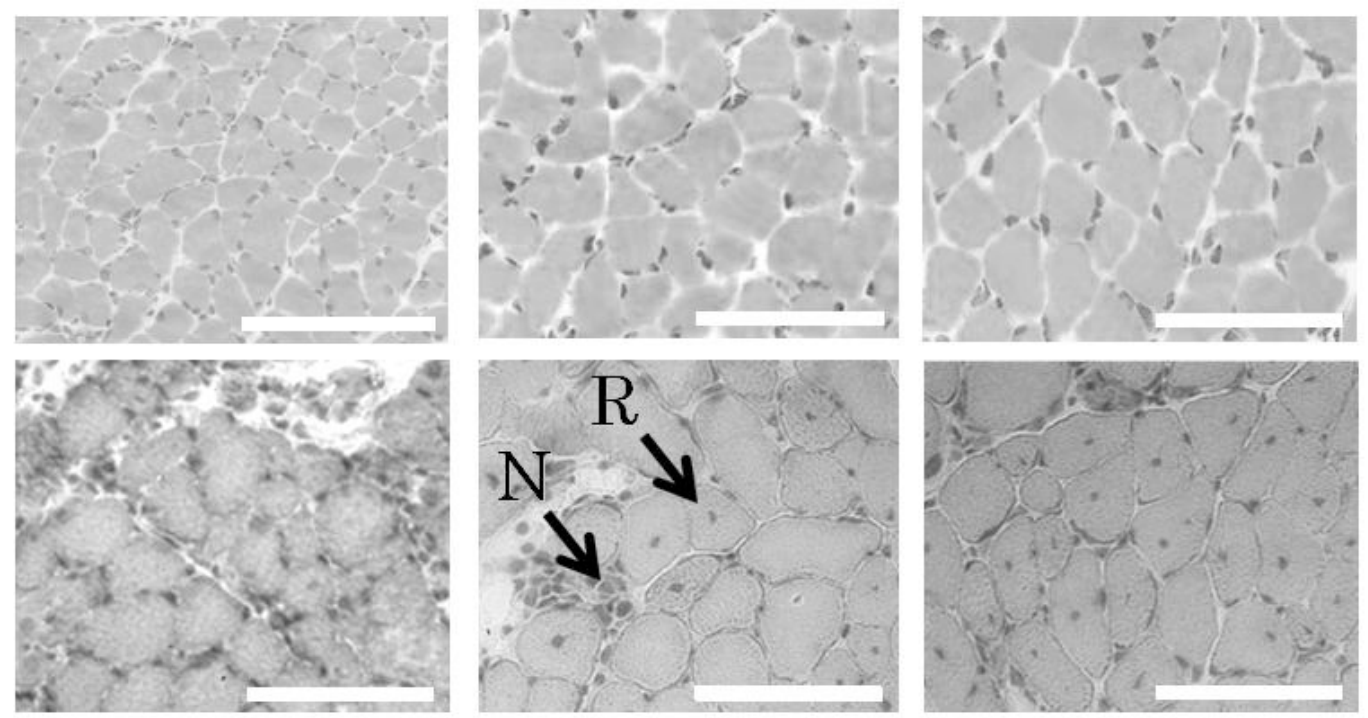

Fig. 1 Representative histological observations from $m d x$ and control mice (B10) at each time point. Scale bars $=100 \mu \mathrm{m}$, H\&E staining. $\mathrm{N}$ : necrotic cell; R: regenerated cell 


\section{Immunohistochemical staining results}

Some muscle cells of 2-week-old $m d x$ mice were positively stained with anti-caspase-12 antibody. Anti-caspase 12 antibodypositive cells were smaller than peripheral cells and had an irregular shape. These cells were somewhat different in morphology from the surrounding cells, and it was suggested that they were in the early stage of necrosis. In the masseter muscle of 3- and 4-week-old $m d x$ mice, many regenerated muscle fibers with centrally located nuclei were observed, but no areas were positively stained with anti-caspase-12 antibody (Figure 2).

In the masseter muscle of control B10 mice at various weeks of age, no areas were positively stained with anti-caspase-12 antibody (Figure 2).

\section{Expression of caspase- 12 mRNA}

The average expression levels of each caspase-12 mRNA from $10 \mathrm{mdx}$ mice and 10 control mice at each time point are shown in Figure 3. The level of caspase-12 mRNA expression was significantly higher in 2-week-old $\mathrm{mdx}$ mice than in control mice, but did not significantly differ between 3 -and 4-week-old $\mathrm{mdx}$ and control mice $(\mathrm{p}<0.05)$.

\section{B10}
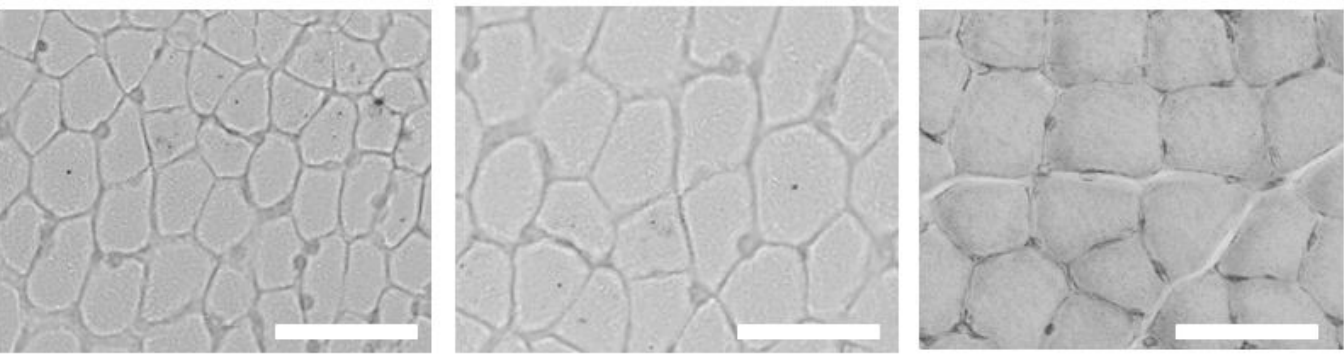

\section{$m d x$}

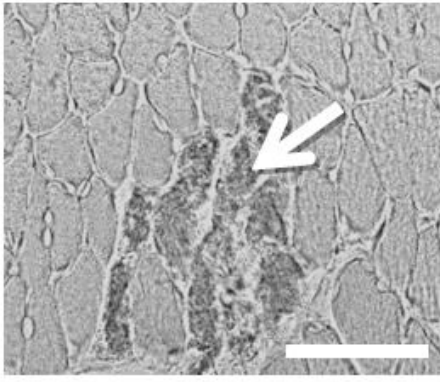

2W

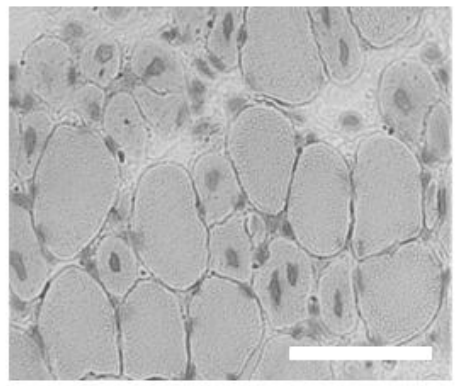

$3 w$

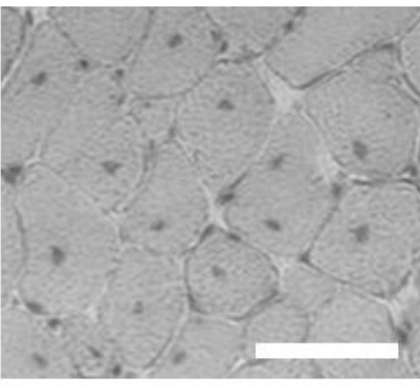

$4 w$

Fig. 2 Immunohistochemical staining results.

Anti-caspase 12 antibody-positive cells were observed in the masticatory muscle of 2-week-old mdx mice (arrow).

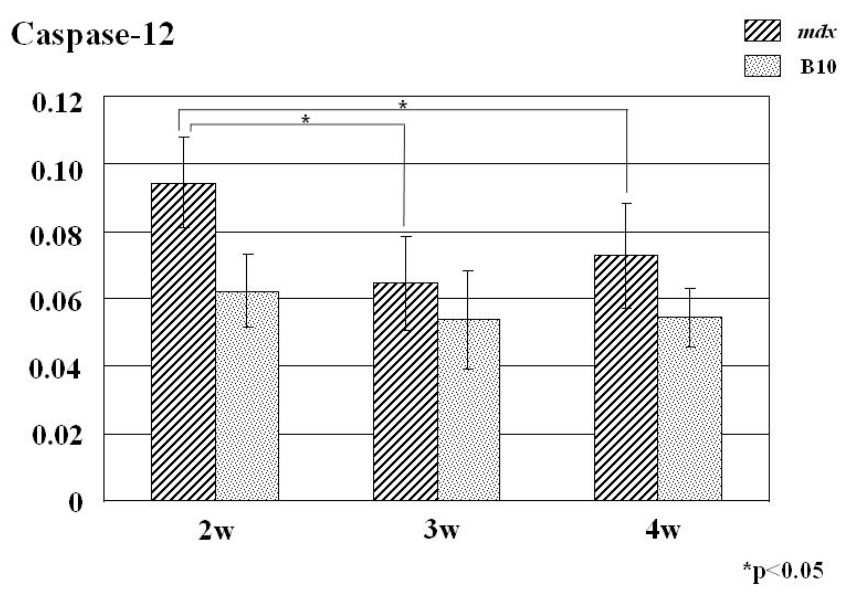

Fig. 3. Average expression level of each caspase-12 mRNA from $m d x$ mice and control mice (B10) at each time point (LightCyclerTM, Values are the mean - SD). Ordinate shows relative gene expression unit as compared to the control housekeeping GAPDH gene. Caspase 12 mRNA expression in the mdx mouse masticatory muscle at 2 weeks of age was significantly higher than that at 3 or 4 weeks of age; however, there were no age-related differences in control mice.

\section{Discussion}

In recent years, it has been reported that intracellular stress generated during myogenesis plays an important role in selecting stress-resistant cells and killing stress-sensitive cells ${ }^{12)}$. In multidisciplinary studies connected with regenerative medicine, inhibitory factors during myogenesis have attracted attention.

Cell death is classified into necrosis according to morphological and biochemical characteristics ${ }^{13)}$. Necrosis is caused by major environmental changes deviating from cell homeostasis, such as ischemia and injury. In contrast, necrosis is closely regulated by intracellular signals, and is not associated with cell membrane disruption, causing little inflammatory reaction; therefore, it has conventionally been considered that physiological cell death proceeds by apoptosis and pathological cell death by necrosis.

The activation cascade of proteases called caspases plays an important role in the execution of apoptosis ${ }^{14,15)}$. Endoplasmic reticulum- and mitochondrial-mediated pathways are known to be involved in their activation. The involvement of endoplasmic reticulum stress-induced apoptosis in the activation of caspase-12 has been suggested ${ }^{16)}$. 
Mitochondrial-mediated pathways have been reported to be involved in the activation of Bax, caspase-9, and caspase- $3{ }^{17}$. Recently, it has been noted that, in addition to necrosis, a phenomenon similar to apoptosis may occur in the muscle fibers of the $m d x$ mouse model of muscular dystrophy. A recent study, investigating overexpression of the caspase- 3 gene related to mitochondrial-mediated necrosis, noted that, in addition to necrosis, a phenomenon similar to apoptosis may occur in the muscle fibers of the $m d x$ mouse model of muscular dystrophy ${ }^{10)}$. In addition, the study analyzed the expression of caspase- $3,-9$, 12 , and Bax during muscle necrosis due to the lack of dystrophin, and investigated mitochondrial and endoplasmic reticulum stress; however, their histological localization has not been ascertained. Therefore, in this study, we immunohistochemically localized the expression of caspase-12, which is known to be involved in endoplasmic reticulum stress, during necrosis of the $m d x$ mouse masseter muscle.
We found that, in the $m d x$ mouse masseter muscle, caspase- 12 was expressed in cells showing a morphology somewhat different from that of the surrounding cells. The level of caspase-12 mRNA expression was also significantly higher in 2-week-old than in control mice. Since caspase-12 is considered to be a necrosisrelated protein induced by endoplasmic reticulum stress ${ }^{16)}$, the results of this study suggest that the lack of dystrophin leads to the generation of stress in muscle fibers to maintain their structure. The reduced caspase-12 expression in the masseter muscle of 3and 4-week-old $m d x$ mice suggested that cell necrosis had already started, and endoplasmic reticulum stress had disappeared. In this study, caspase 12 expression was detected in the masticatory muscle of $m d x$ mice, as previously reported. Concerning tissue localization, which has been unclear, the results suggest that caspase 12 appears in the initial phase of cellular necrosis.

\section{References}

1) Hoffman EP, Brown RH Jr, Kunkel LM. Dystrophin: the protein product of the Duchenne muscular dystrophy locus. Cell 51:919928, 1987.

2) Bulfield G, Siller WG, Wight PA, et al. X chromosome-linked muscular dystrophy $(\mathrm{mdx})$ in the mouse. Proc Natl Acad Sci USA 81:1189-1192, 1984.

3) Dangain J, Vrbova G. Muscle development in mdx mutant mice. Muscle Nerve 7:700-704, 1984

4) DiMario JX, Uzman A, Strohman RC. Fiber regeneration is not persistent in dystrophic (mdx) mouse skeletal muscle. Dev Biol 148:314-321, 1991.

5) Attal P, Lambert F, Marchand-Adam S, et al. Severe Mechanical Dysfunction in Pharyngeal Muscle from Adult mdx Mice. Am J Respir Crit Care Med 162:278-281, 2000.

6) Lee W, Abe S, Kim H, et al. Characteristics of muscle fibers reconstituted in the regeneration process of masseter muscle in an mdx mouse model of muscular dystrophy. J Muscle Res Cell Motil 27: 235-240, 2006

7) Gillis, JM. Membrane abnormalities and $\mathrm{Ca}^{+}$homeostasis in muscles of the mdx mouse, an animal model of the Duchenne muscular dystrophy. Acta Physiol 156:397-406, 1996.

8) Graeber MB, Moran LB. Mechanisms of cell death in neurodegenerative diseases: fashion, fiction, and facts. Brain Pathol 12:385-390, 2002.

9) Mattson MP. Apoptosis in neurodegenerative disorders. Nat Rev Mol Cell Biol 1:120-129, 2000.

10) Mizutani M, Ohno N. Existence of apoptosis related proteins in the mdx mouse masseter muscle. Oral Med Pathol 10:1-7, 2005.
11) Honda A, Abe S, Hiroki E, et al. Activation of caspase 3, 9, 12 and Bax in masseter muscle of mdx mice during necrosis. J Muscle Res Cell Motil 29: 243-247, 2007.

12) Nakanishi K, Sudo T, Morishima N. Endoplasmic reticulum stress signaling transmitted by ATF6 mediates apoptosis during muscle development. The Journal of Cell Biology 169:555-560, 2005.

13) Fink SL, Cookson BT. Apoptosis, pyroptosis, and necrosis: mechanistic description of dead and dying eukaryotic cells. Infect Immun 73:1907-1916, 2005.

14) Friedlander RM, Gonzalez RG, Afridi NA, et al. Case records of the Massachusetts General Hospital. Weekly clinicopathological exercises. Case 16-2003. A 58-year-old woman with left-sided weakness and a right frontal brain mass. N Engl J Med 348:21252132, 2003.

15) Shi Y. Mechanisms of caspase activation and inhibition during apoptosis. Mol Cell 9:459-470, 2002.

16) Nakagawa T, Zhu H, Morishima N, Li E, Xu J, Yankner BA, Yuan J. Caspase-12 mediates endoplasmic-reticulum-specific apoptosis and cytotoxicity by amyloid-beta. Nature 403:98-10, 2000.

17) Earnshaw WC, Martins LM, Kaufmann SH. Mammalian caspases: structure, activation, substrates, and functions during apoptosis. Annu Rev Biochem 68:383-424, 1999. 